\title{
A Construção da Interdisciplinaridade: A área "Sociedade e Meio Ambiente" do Programa de Pós-graduação Interdisciplinar em Ciências Humanas ${ }^{1}$
}

\author{
The Construction of Interdisciplinarity: \\ The area "Society and Environment" at the Interdisciplinary Ph.D. in \\ Human Sciences
}

\author{
Ivana Cristina Lovo ${ }^{2}$ \\ Mariuze Dunajski Mendes ${ }^{3}$ \\ Jerônimo Siqueira Tybusch ${ }^{4}$
}

\section{RESUMO}

O presente artigo analisa a produção científica da área "Sociedade e Meio Ambiente" do Programa de Pós-graduação Interdisciplinar em Ciências Humanas da Universidade Federal de Santa Catarina (UFSC), Florianópolis/SC, no período compreendido de 1999 a 2007. O objetivo central é observar e tecer considerações sobre a construção da interdisciplinaridade nas obras dos alunos desse programa. Observa-se na pesquisa a abordagem interdisciplinar como um processo, uma construção conjunta, onde diversas disciplinas e autores dialogam na percepção de um objeto de forma profunda, conectando múltiplas dimensões de espaço e tempo.

Palavras-Chave: Doutorado Interdisciplinar em Ciências Humanas. Sociedade e Meio Ambiente. Interdisciplinaridade.

\section{ABSTRACT}

This article examines the scientific knowledge produced by the area "Society and Environment" at the Post-Graduate Program of Interdisciplinary in Human Sciences at the 'Universidade Federal de Santa Catarina' (UFSC), Florianópolis/SC, through the years 1999 to 2007 . The main purpose is to observe and to analyze the construction of the interdisciplinary approaches in the Students' Thesis of this program. It was noticed that in the research the interdisciplinary approach as a process, a joint construction, where several disciplines and authors dialogue on the perception of an object in a deep way, connecting multiple dimensions of space and time.

\footnotetext{
${ }^{1}$ Trabalho apresentado como conclusão da disciplina de Epistemologia e Metodologia de Pesquisa do Doutorado Interdisciplinar em Ciências Humanas (DICH), sob a orientação da Profa. Dra. Carmen Silvia de Moraes Rial. Segundo semestre de 2007.

2 Mestra em Botânica. Doutoranda no Programa de Pós-Graduação Interdisciplinar em Ciências Humanas da UFSC. ivanalovo@gmail.com

${ }^{3}$ Mestra em Tecnologia. Doutoranda no Programa de Pós-Graduação Interdisciplinar em Ciências Humanas da UFSC. mariuzemendes@gmail.com

${ }^{4}$ Mestre em Direito Público. Doutorando no Programa de Pós-Graduação Interdisciplinar em Ciências Humanas da UFSC. jeronimotybusch@gmail.com
} 
Key-Words: Interdisciplinary Ph.D. in Human Sciences. Society and Environment. Interdisciplinarity.

\section{INTRODUZINDO O TEMA DA INTERDISCIPLINARIDADE: O CAMINHO METODOLÓGICO}

A questão da interdisciplinaridade tem sido tema recorrente na discussão e construção de currículos da graduação e pós-graduação, na busca de um caminho a ser trilhado, de forma coerente e complexa, permitindo abordagens que interrelacionem visões diversas sobre temas específicos.

Em geral, cursos de pós-graduação da Área Interdisciplinar são desafiados quanto à diferenciação das práticas disciplinares e quanto à identificação da construção de caminhos próprios da interdisciplinaridade, que envolvem, por exemplo: a definição da matriz curricular, a dinâmica ensino-aprendizagem, a natureza científica e epistemológica das pesquisas, o retorno à comunidade científica e à sociedade dos resultados das teses, etc.

Há diferentes concepções sobre a abordagem interdisciplinar. Enrique Leff (2000), por sua vez, enfatiza a inter-relação de processos acadêmicos e práticos, conforme descreve a seguir:

A interdisciplinaridade implica assim um processo de inter-relação de processos, conhecimentos e práticas que transborda e transcende o campo da pesquisa e do ensino no que se refere estritamente às disciplinas científicas e a suas possíveis articulações. Dessa maneira, o termo interdisciplinaridade vem sendo usado como sinônimo e metáfora de toda interconexão e "colaboração" entre diversos campos do conhecimento e do saber dentro de projetos que envolvem tanto as diferentes disciplinas acadêmicas, como as práticas não científicas que incluem as instituições e atores sociais diversos (LEFF, 2000, p.22)

Já José Coimbra (2000) salienta o vínculo acadêmico e prático da palavra interdisciplinaridade, enfatizando que o termo traduz tal vínculo não apenas entre saberes, mas, principalmente, de um saber para com outro saber, ou dos saberes entre 
si, numa sorte de complementaridade, de cumplicidade solidária, em função da realidade estudada e conhecida.

$\mathrm{Na}$ confluência das definições do que é a interdisciplinaridade — apresentada nas teses analisadas neste ensaio - podemos caracterizar a abordagem interdisciplinar como um processo, uma construção conjunta, onde diversas disciplinas e autores dialogam na percepção de um objeto de forma profunda, conectando as dimensões de espaço e tempo.

A questão que norteia este ensaio consiste em tentar compreender, por meio da análise de teses defendidas entre 1999 a 2007, como a interdisciplinaridade tem sido construída no Programa de Pós-Graduação Interdisciplinar em Ciências Humanas PPICH, da Universidade Federal de Santa Catarina (UFSC) e, dessa forma, tentar contribuir com reflexões sobre o tema a partir de visões diversas apontadas pelos/as autores/as.

Foram analisadas 24 teses das 38 defendidas até 2007, sendo as mesmas divididas entre os quatro doutorandos da área de Sociedade e Meio Ambiente que fizeram a disciplina Epistemologia e Metodologia de Pesquisa oferecida no segundo semestre de 2007, coordenada pela professora Dra. Carmen Silvia de Moraes Rial. A escolha das teses a serem analisadas pelos doutorandos ocorreu de forma aleatória, permitindo uma análise a partir de diferentes pontos de vista, notadamente marcados pela formação e área de origem dos mesmos: Artes, Direito, Ciências Humanas e Biologia. Além de ser importante ressaltar esta diversidade de formação, também constatamos que nem sempre tal formação de origem é a mesma da área de atuação ou pesquisa, dado que já demonstra por si só o trânsito por várias áreas do conhecimento, marca do Doutorado Interdisciplinar em Ciências Humanas (DICH) da UFSC.

As varáveis a serem analisadas foram definidas durante as aulas da disciplina Epistemologia e Metodologia de Pesquisa, com o intuito de balizar o processo investigativo. As eleitas para o recorte epistemológico foram:

1. formação e atividade desenvolvida ou em desenvolvimento pelo autor;

2. contexto do tema; 
3. disciplinas que embasaram as investigações e a hierarquia entre elas;

4. problemática e pergunta da pesquisa;

5. objetivo geral e específicos;

6. revisão de literatura;

7. procedimentos metodológicos de coleta e análise dos dados;

8. apresentação, análise e interpretação dos resultados.

A partir da análise das teses que cada doutorando/a ficou responsável, dois caminhos foram trilhados pelo grupo da área "Sociedade e Meio Ambiente", um em que se optou por elaborar planilhas com o objetivo de demonstrar de forma sintética o resultado do conjunto de teses analisadas para subsidiar a elaboração de textos, caminho adotado por duas autoras. Outro caminho, trilhado pelos outros dois, foi o de incorporar a análise das teses diretamente na elaboração do artigo da área.

Trilhar caminhos distintos consiste no objetivo da metodologia de pesquisa. Caminhos nem sempre retos, nem sempre fáceis, mas sempre negociáveis e flexíveis. A negociação foi a marca deste ensaio. Negociação de sentidos, de correntes do pensamento, de formas de abordagem ou como leitor vai receber o conhecimento produzido pelas análises. Este processo contribuiu para vivenciar a prática interdisciplinar.

\section{SOCIEDADE E MEIO AMBIENTE: A INTERFACE DA COMPLEXIDADE E A COMUNICAÇÃO NA PESQUISA APLICADA}

Observa-se que para uma variedade de problemas complexos, soluções simplificadoras não bastam. O pensamento simplificador é incapaz de conceber a conjunção do uno e do múltiplo: ou ainda unifica abstratamente ao anular a diversidade, ou, pelo contrário, justapõe a diversidade sem conceber a unidade (MORIN, 2003). Porém, nessa dialética da criação os obstáculos não tardam por vir e são marca de uma sociedade complexa. Por isso, pensar em criação é pensar em risco, contingência, paradoxo, tempo, bem como no problema espaço/temporal da globalização. 
A sociedade complexa é definida por Gilberto Velho (1987) como

Uma sociedade na qual a divisão social do trabalho e a distribuição de riquezas delineiam categorias sociais distinguíveis com continuidade histórica, sejam classes sociais, estratos, castas. [...] A noção de complexidade traz também a idéia de uma heterogeneidade cultural que deve ser entendida como coexistências, harmoniosas ou não, de uma pluralidade de tradições cujas bases podem ser ocupacionais, étnicas, religiosas, entre outras. (VELHO,1987, p.16) [grifos no original]

Esta definição é central em sua proposta, pois mostra a delimitação e fronteiras simbólicas e estilos de vida em relação a categorias sociais, que definem identidades. Neste ponto podemos aproximar a definição do autor ao multiculturalismo apresentado por Stuart Hall (2003) em suas teorias sobre identidades e fronteiras culturais, apontando para uma fragmentação de papéis, ligados a contextos de inserção social e cultural, podendo o indivíduo desempenhar diferentes papéis dependendo de interesses pessoais e/ou projetos coletivos.

As sociedades complexas surgiram a partir da Revolução Industrial, sendo marcadas pelo aumento da produção e do consumo e por uma acentuada divisão social do trabalho. Têm como locus as grandes metrópoles e como problema básico a "contradição entre as particularizações de experiências restritas a certos segmentos, categorias, grupos e até indivíduos e a universalização de outras experiências que se expressam culturalmente através de conjuntos de símbolos homogeneizadores paradigmas, temas etc." (Velho, 1987, p.18) [grifos no original]. Esta distinção dos indivíduos pelos códigos mais restritos ou universalizantes, a partir de suas redes de relações (que mudam com o passar do tempo nas interações sociais, não sendo, portanto, fixas), são compartilhadas em formas de linguagem - circunscritas em campos de comunicação particulares ou universais e em categorias sociais - que dão diferentes significados à informação veiculada, a partir de seus repertórios culturais. Esta comunicação segmentada e hierarquizada e o domínio de códigos específicos, podendo funcionar, como aponta Pierre Bourdieu (1980), como uma forma de exclusão e dominação.

As relações sociais estão ligadas a um projeto (enquanto um conjunto de idéias) localizados no tempo e no espaço, sendo tal projeto, para Velho (1987, p.22), uma 
"tentativa consciente de dar um sentido e uma coerência a essa experiência fragmentadora" das sociedades complexas, em que os diferentes papéis sociais, ligados a distintos contextos, determinam incompatibilidades e contradições na comunicação entre as pessoas e grupos. Ele detalha:

Um projeto social, que englobe vários indivíduos depende de uma percepção e vivência de interesses comuns [...] A estabilidade e eficácia destes projetos dependerão de sua capacidade de estabelecer uma definição de realidade convincente, coerente e gratificante - em outras palavras, de sua eficácia simbólica e política propriamente dita (VELHO, 1987, p.32) [grifos no original]

Neste ponto o autor destaca o papel político dos projetos sociais, que serão mais eficazes quanto maior sua plasticidade simbólica e potencial de metamorfosear-se, indo no sentido em que também apontam Homi Bhabha (2001), Hall (2003), Néstor Garcia Canclini (1997), de interpenetração de repertórios e fluidez de fronteiras. Os estilos de vida e as visões de mundo são, ao mesmo tempo, centrados e em trânsito, abrindo para discursos, em referência ao outro e ao social, em "interações interpretadas".

Os projetos têm sempre uma dimensão cultural, social, histórica, econômica e política, estando ligados à organização social e aos processos de mudança social, implicando em "relações de poder". A capacidade de difusão e transformação que os projetos podem ter está diretamente ligada ao

instrumental simbólico que puderem manipular, dos paradigmas a que estiverem associados, da capacidade de contaminação e difusão da linguagem que for utilizada, mais ou menos restrita, mais ou menos universalizante. $O$ potencial de compreensão de um projeto social depende do conjunto de símbolos a que está associado e que veicula (VELHO, 1987, p.34).

Dialogando com o autor, podemos ressaltar a importância de estabelecer pontes entre várias áreas do conhecimento (antropologia, história, filosofia, sociologia, psicologia, entre outras) para compreender as modernas sociedades complexas em que vivemos e para pensar todo o processo de comunicação que se estabelece, tanto no sentido de homogeneização e dominação, quanto de resistência e contestação. $O$ caráter coletivo e individual das vivências cotidianas, quanto mais relacionados a redes de significados culturais de grupos e maior for o compartilhamento de repertórios dos gêneros discursivos - interpenetrando domínios e fronteiras - maior será a chance de comunicação e do sucesso de um projeto social.

Cad. de Pesq. Interdisc. em Ci-s. Hum-s., Florianópolis, v.10, n.97, p. 27-52, jul./dez. 2009 
Este cenário inclui novas formatações em relação aos avanços tecnológicos, aos diretos humanos, questões ecológicas e também problemas ligados à natureza em mudança da família, trabalho e identidade pessoal e cultural, justiça social e emancipação (GIDDENS, 1999). Todos interligados e conectados entre si numa grande rede de informações/interações.

Quanto mais estudamos os principais problemas de nossa época, mais somos
levados a perceber que eles não podem ser entendidos isoladamente. São
problemas sistêmicos, o que significa que estão interligados e são
interdependentes. Por exemplo, somente será possível estabilizar a população
quando a pobreza for reduzida em âmbito mundial. A extinção de espécies
animais e vegetais numa escala massiva continuará enquanto o Hemisfério
Meridional estiver sob o fardo de enormes dívidas. A escassez dos recursos e a
degradação do meio ambiente combinam-se com populações em rápida
expansão, o que leva ao colapso das comunidades locais e à violência étnica e
tribal que se tornou a característica mais importante da era pós-guerra fria.
(CAPRA, 2003, p. 23).

A revolução das comunicações e a difusão da tecnologia da informação estão profundamente ligadas a "processos de globalização" (GIDDENS, 1999, p.41). Em meio às certezas da sociedade industrial, baseadas em consensos e perspectivas de progresso que camuflam os riscos e relações (um falso otimismo), nasce uma sociedade dinâmica. Tal sociedade, "[...] não é uma opção que se pode escolher ou rejeitar no decorrer de disputas políticas. Ela surge na continuidade dos processos de modernização autônoma, que são cegos e surdos em relação a seus próprios efeitos e ameaças" (BECK, 1997, p.20).

Ao refletir sobre a Sociedade em relação com o Meio Ambiente, somos levados a pensar mais detidamente sobre os conceitos de "Ecologia" e "Cena Ecológica", que se configuram como fundamentais para algumas teses do programa.

O conceito de 'ecologia' origina-se do vocábulo grego oikos que significa literalmente "casa", "moradia". Paradoxalmente, o mesmo prefixo dá origem à palavra economia. Duas palavras em constante embate na contemporaneidade, ecologia e economia. Já o conceito que preferimos adotar acerca da ecologia neste trabalho é um pouco mais complexo.

Tal concepção é elaborada por Edgar Morin (2001) e compreende uma ecologia derivada de um ecossistema como auto-organizador e co-programador do sistema vivo 
que nele se encontra integrado. A autonomia supõe complexidade, pois um sistema vivo é autônomo, mas é dependente do ecossitema. Complexidade na relação paradoxal. Ou seja, autônomo porque dependente e dependente porque autônomo.

Além do elemento complexidade, o conceito de Edgar Morin (2001) acerca da ecologia agrega a multidependência em relação ao sistema social. A sociedade humana mais emancipada em relação à natureza, nutrindo sua autonomia na multidependência. Inclui-se no conceito, portanto, o elemento antropos. Assim, ecologia para o autor compreenderia: Auto-organização Ecossistêmica - Complexidade Consciência - Condições Bio-antropológicas e Sócio-Culturais ou Nosológicas.

A ecologia aumenta a complexidade e os questionamentos acerca de algumas informações que eram já consideradas como absolutas verdades no campo científico, forçando o sistema a executar reiteradas vezes a operação relativa a códigos acerca das novas comunicações que surgem no próprio sistema, fruto de sua atividade reflexiva.

A questão informacional assume proporções gigantescas na cena ecológica. Sua veiculação é importantíssima para a compreensão da importância em preservar o meio em que vivemos para as gerações futuras, a fim de que possamoos prever o alcance de nossas tecnologias e os riscos oriundos de nossas atividades.

Entende-se como "cena ecológica", portanto, o conjunto de práticas discursivas produzidas na atualidade acerca da possível finitude humana em face da ação degradante e insustentável dos sistemas de produção, lazer e consumo mundial que, através dos meios de comunicação de massa, perpassam as diferentes culturas no globo. Na esteira desta perspectiva analisa-se como o discurso da pós-modernidade produz sentimentos específicos acerca deste fenômeno. 


\section{A DIMENSÃO DO CONHECIMENTO E DAS IDEIAS NA CONSTRUÇÃO DA PESQUISA INTERDISCIPLINAR EM CIÊNCIAS HUMANAS NO FOCO "SOCIEDADE E MEIO AMBIENTE"}

Michel Foucault (2004) opta por uma "arqueologia das ideias" ao invés de uma "história das ideias", fugindo da linearidade e do simples reconstituir o que pôde ser pensado, desejado, visado, experienciado ou almejado pelos homens no próprio instante em que proferiam o discurso, não sendo o retorno do homem ao próprio segredo da origem e sim, a descrição sistemática de um discurso objeto que busca definir os próprios discursos, enquanto práticas que obedecem às regras (FOUCAULT, 2004). Segundo destaca:

A arqueologia busca definir não os pensamentos, as representações, as imagens, os temas, as obsessões que se ocultam ou se manifestam nos discursos, mas os próprios discursos, enquanto práticas que obedecem a regras. Ela não trata o discurso como documento, como signo de outra coisa, como elemento que deveria ser transparente, mas cuja opacidade importuna é preciso atravessar frequentemente para reencontrar, enfim, aí onde se mantém à parte, a profundidade do essencial; ela se dirige ao discurso em seu volume próprio, na qualidade de monumento. Não se trata de uma disciplina interpretativa: não busca um "outro discurso" mais oculto. Recusa-se a ser alegórica (FOUCAULT, 2004, p.157).

Desta forma, compreendemos que a comunicação ecológica influencia nos registros da dimensão histórica, possibilitando uma atitude de reflexividade por parte dos Sistemas de Conhecimento envolvidos, que através de um processo arqueológico revê suas estruturas.

O conhecimento (entendido como um ato sócio-histórico) ocorre nas fronteiras entre os gêneros discursivos, primários e secundários ${ }^{5}$ (BAKHTIN, 2002), sempre em tensão, mas sempre se mesclando. Assim, falar em modernidade, como cita também Jacques Le Goff (1990), significa pensá-la como algo inacabado, em dúvida e sujeito a

\footnotetext{
${ }^{5}$ Os gêneros primários são os da ideologia do cotidiano (relação direta com os contextos mais imediatos) e os gêneros secundários são dos sistemas ideológicos constituídos (filosofia, religião, arte, educação formal). Os dois gêneros não devem ser considerados hierárquicos. Um não deve sobrepujar o outro e nem serem abstraídos de suas esferas originais (BAKTIN, 2002, p.117).
}

Cad. de Pesq. Interdisc. em Ci-s. Hum-s., Florianópolis, v.10, n.97, p. 27-52, jul./dez. 2009 
críticas. Modernidade e tradição estão muito próximas, ligadas pela memória e história, uma vez que:

O 'moderno', à beira do abismo do presente, volta-se para o passado. Se por um lado recusa o antigo, tende a refugiar-se na história. Modernidade e moda retrô caminham lado a lado. Este período que se diz e quer totalmente novo, deixa-se obcecar pelo passado: memória, história (LE GOFF, 1990, p.198).

A tomada de consciência ecológica do futuro é dependente do nosso passado e não se contentará somente com fatores ambientais, mas terá como objeto também as devastações ecológicas no campo social e no domínio mental. Esta preocupação considera o social em toda a sua complexidade. O social que exige ser resingularizado, re-trabalhado e re-experimentado. Transfere-se a singularidade do artista criador de espaços para a subjetividade coletiva. Esta interação entre a criatividade individual e as múltiplas coações materiais e sociais conhece a veracidade no tensionamento.

O "todo unificado" é uma abstração, pois não existe uma manifestação que se mantenha homogênea, inalterada e pura ao longo da história. As vontades coletivas promovem uma dinâmica que pode recuperar, manter ou renovar as tradições, reorganizando os elementos, articulando as diferentes práticas, que adquirem novos significados e relevância. (HALL, 2003b).

Assim, não se poderá mais definir a cidade somente em termos de espacialidade, mas deverá processar transdisciplinarmente o cruzamento de questões históricas-geológicas-antropológicas-tecnológicas-políticas-jurídicas-econômicas-sócioculturais. É muito comum o desconhecimento desse aspecto global das problemáticas urbanas como meio de produção da subjetividade (GUATTARI, 1992). O objeto arquitetural e o objeto urbanístico-ecológico adquirem a textura de enunciador subjetivo, ou seja, comunicam.

O pensamento cientificista oriundo da Modernidade permitiu o confinamento generalizado das subjetividades, a separação dos espaços sociais e a ruptura dos modos de dependência. Não obstante, o mundo contemporâneo exige uma nova forma de pensar e de agir que repudie os sistemas fechados; as estatísticas e as pesquisas de opinião, a histeria do consumo e inaugure uma era de relações mais afetuosas entre 
as pessoas, de curiosidade pelo mundo interior do outro, de substituição da angústia e da ansiedade pela sabedoria diante dos fatos naturais da vida.

A perspectiva ecológica exige a formação de um pensamento que reflita a heterogeneidade, a possibilidade da diferença, a tolerância e a solidariedade diante do outro. É preciso conceber uma sociedade na qual estejam desde sempre colocados múltiplos modos de viver e construir a realidade.

A perspectiva construtivista é uma das correntes teóricas que concentra sua aplicação em explicar como a inteligência humana se desenvolve partindo do princípio de que o desenvolvimento da mesma é determinado pelas ações mútuas entre o indivíduo e o meio. A compreensão é norteada para o fato de que o homem constrói saberes, eliminando a idéia de um conhecimento "pré-dado". Ele responde aos estímulos externos agindo sobre eles para construir e organizar o seu próprio conhecimento, de forma cada vez mais elaborada.

Tal concepção apresentou profundos avanços para uma mudança de percepção epistemológica, contribuindo diretamente nos processos educacionais. Essa visão preconiza a não acomodação às situações dadas criando, portanto, diferentes discursos sociais que mantêm vivas as estruturas das classes e é nas lutas de classe que os discursos monologizantes ${ }^{6}$ perdem a força, garantindo a sobrevivência das comunidades. Isto só ocorre nas estruturas sociais organizadas, onde para Mikhail Bakhtin (2002, p.66), "o signo se torna a arena onde se desenvolve a luta de classes”. A compreensão dos significados envolve o entendimento de posições contraditórias e complementares, sendo a palavra expressão do momento vivido, "como produto da interação viva das relações sociais" (BAKHTIN, 2002, p. 66).

\footnotetext{
${ }^{6}$ Discurso monologizante, segundo Bakhtin, é aquele baseado em forças centrípetas, que querem ser sempre a palavra final. Ou seja, é um discurso centralizador que reifica o "outro" (BAKHTIN, 2002).
} 


\section{O DOUTORADO INTERDISCIPLINAR EM CIÊNCIAS HUMANAS E A ÁREA "SOCIEDADE E MEIO AMBIENTE": UMA BREVE CONTEXTUALIZAÇÃO HISTÓRICA E EPISTEMOLÓGICA}

O Programa de Pós-Graduação Interdisciplinar em Ciências Humanas da UFSC foi iniciado em 1995, tendo por objetivo principal "desenvolver atividades de ensino e pesquisa de caráter interdisciplinar". Iniciou a partir da "convergência temática de um grupo de professores/as-pesquisadores/as provenientes das disciplinas de Antropologia, Ciência Política, Filosofia, Geografia, História, Psicologia e Sociologia"7 .

O Programa atualmente conta com três áreas de concentração: Sociedade e Meio Ambiente (SMA); Condição Humana na Modernidade (CHM) e Estudos de Gênero (EGE).

A área de SMA foi a primeira a ser implantada tendo, portanto, um caminho interdisciplinar mais longo, demonstrado nas teses até hoje defendidas. Foram 38 teses de 1999 até 2007, conforme apresentado no quadro 1 a seguir:

\begin{tabular}{|c|c|c|c|}
\hline \multicolumn{4}{|c|}{ Relação das Teses defendidas na área de Sociedade e Meio Ambiente } \\
\hline ANO & DOUTOR (A) & TÍTULO & ORIENTAÇÃO \\
\hline 2007 & $\begin{array}{l}\text { Maria Carolina } \\
\text { Martinez } \\
\text { Andion }\end{array}$ & $\begin{array}{l}\text { Atuação Das Ongs Nas Dinâmicas De Desenvolvimento } \\
\text { Territorial Sustentável No Meio Rural De Santa Catarina: } \\
\text { Os Casos Da Apaco, Do Centro Vianei De Educação } \\
\text { Popular E Da Agreco. }\end{array}$ & $\begin{array}{l}\text { Orientador: } \quad \text { Paulo } \\
\text { Henrique Freire Vieira; Co- } \\
\text { orientador: Ademir Antônio } \\
\text { Cazella }\end{array}$ \\
\hline 2007 & $\begin{array}{l}\text { Ana Lúcia } \\
\text { Santos } \\
\text { Verdasca } \\
\text { Guimarães }\end{array}$ & $\begin{array}{l}\text { Design, Sociedade E Cultura: Significados dos Arranjos } \\
\text { Espaciais e dos Objetos Em Interiores Domésticos }\end{array}$ & $\begin{array}{lr}\text { Orientadora: } & \text { Tamara } \\
\text { Benakouche; } & \text { co- } \\
\text { orientadora: Carmen Rial }\end{array}$ \\
\hline 2007 & $\begin{array}{l}\text { Valdir Aquino } \\
\text { Zitzke }\end{array}$ & $\begin{array}{l}\text { A Rede Sociotécnica Da Usina Hidrelétrica Do Lageado } \\
\text { (To) E Os Reassentamentos Rurais Das Famílias } \\
\text { Atingidas }\end{array}$ & $\begin{array}{l}\text { Orientadora: Júlia Silvia } \\
\text { Guivant; Co-orientadora: } \\
\text { Maria José Reis }\end{array}$ \\
\hline 2007 & $\begin{array}{l}\text { Edonilce Da } \\
\text { Rocha Barros }\end{array}$ & $\begin{array}{l}\text { Arranjos Socioprodutivos da Agricultura Familiar de } \\
\text { Adaptação A Uma Dinâmica Territorial de } \\
\text { Desenvolvimento }\end{array}$ & $\begin{array}{l}\text { Orientador: } \quad \text { Paulo } \\
\text { Henrique Freire Vieira; Co- } \\
\text { orientador: Jean-Philippe } \\
\text { Tonneau }\end{array}$ \\
\hline 2006 & $\begin{array}{l}\text { Cíntia Uller } \\
\text { Gómez }\end{array}$ & $\begin{array}{l}\text { Agricultura Familiar e Participação na Gestão das Águas } \\
\text { na Bacia do Itajaí (SC,Brasil) }\end{array}$ & $\begin{array}{l}\text { Orientador: Luiz F. F. } \\
\text { Scheibe; co-orientadora: } \\
\text { Maria José Reis }\end{array}$ \\
\hline 2006 & $\begin{array}{l}\text { Elisabeth } \\
\text { Cristhmann } \\
\text { Ramos }\end{array}$ & $\begin{array}{l}\text { Abordagem Naturalista na Educação Ambiental. Uma } \\
\text { Análise dos Projetos Amibientais de Educação em } \\
\text { Curitiba }\end{array}$ & $\begin{array}{lr}\text { Orientador: } & \text { Selvino } \\
\text { Assmann; co-orientador } \\
\text { Luiz Fernando Scheibe }\end{array}$ \\
\hline 2006 & $\begin{array}{l}\text { Claudia Lucia } \\
\text { Bisaggio }\end{array}$ & $\begin{array}{l}\text { Moeda Social - uma análise interdisciplinar de suas } \\
\text { pontencialidades no Brasil contemporâneo }\end{array}$ & $\begin{array}{l}\text { Orientador: Ary Minella; } \\
\text { co-orientador: Héctor Leis }\end{array}$ \\
\hline
\end{tabular}

\footnotetext{
${ }^{7}$ Tais informações podem ser encontradas no site do programa: http://www.cfh.ufsc.br/ dich/.
} 


\begin{tabular}{|c|c|c|c|}
\hline & Soares & & \\
\hline 2005 & $\begin{array}{l}\text { Angela Maria } \\
\text { de Moraes } \\
\text { Bertho }\end{array}$ & $\begin{array}{l}\text { Os Índios Guarani da Serra do Tabuleiro e a } \\
\text { Conservação da Natureza - etnohistória/ cosmologia/ } \\
\text { territorialidade/ manejo agroflorestal/ sustentabilidade } \\
\text { etnoambiental }\end{array}$ & $\begin{array}{l}\text { Orientador: Luiz Fernando } \\
\text { Scheibe; co-orientador: } \\
\text { Silvio Coelho dos Santos }\end{array}$ \\
\hline 2005 & $\begin{array}{l}\text { Fernando } \\
\text { Oliveira Noal }\end{array}$ & $\begin{array}{l}\text { Ciência, Técnica e Ética: o princípio da responsabilidade } \\
\text { de Hans Jonas e suas interfaces com as questões } \\
\text { ecológicas contemporâneas }\end{array}$ & $\begin{array}{l}\text { Orientador: Paulo Freire } \\
\text { Vieira; co-orientador: } \\
\text { Franz Brüseke }\end{array}$ \\
\hline 2004 & $\begin{array}{l}\text { Júlio César } \\
\text { Refosco }\end{array}$ & $\begin{array}{l}\text { Mudanças no Uso da Terra: o caso da bacia do Itajaí/SC } \\
\text { a partir de um modelo dinâmico }\end{array}$ & $\begin{array}{l}\text { Orientador: Luiz F. } \\
\text { Scheibe; co-orientador: Ivo } \\
\text { Marcos Theis }\end{array}$ \\
\hline 2004 & $\begin{array}{l}\text { Brena Paula } \\
\text { Magno } \\
\text { Fernandez }\end{array}$ & $\begin{array}{l}\text { O Devir das Ciências:Isenção ou Inserção de Valores } \\
\text { Humanos? Por uma ciência econômica ética, social e } \\
\text { ecologicamente comprometida }\end{array}$ & $\begin{array}{lr}\text { Orientador: } & \text { Alberto } \\
\text { Cupani; } & \text { co-orientador: } \\
\text { Paulo Freire Vieira } & \end{array}$ \\
\hline 2004 & Eliane Dalmora & $\begin{array}{l}\text { O Papel da Agricultura Familiar no Processo de } \\
\text { Conservação da Mata Atlântica em Santa Catarina. } \\
\text { Modos de Apropriação e Transformações no Sistema de } \\
\text { Gestão Ambiental na Década de } 1990\end{array}$ & $\begin{array}{l}\text { Orientador: Paulo Freire } \\
\text { Vieira; co-orientador: Eros } \\
\text { Marion } \quad \text { Mussoi }\end{array}$ \\
\hline 2004 & $\begin{array}{l}\text { Agripa Faria } \\
\text { Alexandre }\end{array}$ & Ambientalismo Político, Seletivo e Diferencial no Brasil & $\begin{array}{lr}\text { Orientador: } & \text { Paulo } \\
\text { Krischke; co-orientador: } \\
\text { Selvino Assmann }\end{array}$ \\
\hline 2003 & $\begin{array}{l}\text { Hélio dos } \\
\text { Santos Silva }\end{array}$ & $\begin{array}{l}\text { Análise Sociotécnica da Meteorologia Brasileira: uma } \\
\text { aplicação para o vale do Itajaí/SC }\end{array}$ & $\begin{array}{lr}\text { Orientador: } & \text { Tamara } \\
\text { Benakouche; } & \text { co- } \\
\text { orientador: Pedro Leite da } \\
\text { Silva Dias }\end{array}$ \\
\hline 2003 & $\begin{array}{l}\text { Luiz Carlos } \\
\text { Mior }\end{array}$ & $\begin{array}{l}\text { Agricultores Familiares, Agroindústrias e Território: a } \\
\text { dinâmica das redes de desenvolvimento rural no Oeste } \\
\text { Catarinense }\end{array}$ & $\begin{array}{l}\text { Orientadora: Júlia Guivant; } \\
\text { co-orientador: } \quad \text { Terry } \\
\text { Marsden }\end{array}$ \\
\hline 2003 & $\begin{array}{l}\text { Luiz Alberto } \\
\text { Ferreira }\end{array}$ & $\begin{array}{l}\text { Formação Técnica para o Ecodesenvolvimento: uma } \\
\text { avaliação do ensino técnico agrícola em Santa Catarina } \\
\text { no período 1992-2002 }\end{array}$ & $\begin{array}{ll}\text { Orientador: } & \text { Paulo Freire } \\
\text { Vieira; } & \text { co-orientador: } \\
\text { Ademir Antonio Cazella }\end{array}$ \\
\hline 2003 & $\begin{array}{l}\text { Alvaro Afonso } \\
\text { Simon }\end{array}$ & $\begin{array}{l}\text { Extensão Rural em Microbacias Hidrográficas como } \\
\text { Estratégia de Gestão Ambiental no Meio Rural } \\
\text { Catarinense: a qualidade dos sistemas sociais e } \\
\text { ecológicos como um patrimônio comum }\end{array}$ & $\begin{array}{lr}\text { Orientador: } & \text { Fernando } \\
\text { Scheibe; co-orientador: } \\
\text { César Augusto Pompêo }\end{array}$ \\
\hline 2003 & $\begin{array}{l}\text { Cristiane } \\
\text { Mansur de } \\
\text { Moraes e } \\
\text { Souza }\end{array}$ & $\begin{array}{l}\text { Avaliação Ambiental Estratégica como Subsídio para o } \\
\text { Planejamento Urbano }\end{array}$ & $\begin{array}{lr}\text { Orientador: } & \text { Fernando } \\
\text { Scheibe; } & \text { co-orientador: } \\
\text { Erni Seibel } & \end{array}$ \\
\hline 2003 & $\begin{array}{l}\text { Rosana Maria } \\
\text { Badalotti }\end{array}$ & $\begin{array}{l}\text { A Cooperação Agrícola e a Agroecologia como Base } \\
\text { para a Viabilização da Agricultura Familiar no Oeste } \\
\text { Catarinense: o papel da APACO (Associação dos } \\
\text { Pequenos Agricultores do Oeste Catarinense) }\end{array}$ & $\begin{array}{l}\text { Orientadora: Maria José } \\
\text { Reis; co-orientador: Héctor } \\
\text { Leis }\end{array}$ \\
\hline 2003 & $\begin{array}{l}\text { Vera Iten } \\
\text { Teixeira }\end{array}$ & $\begin{array}{l}\text { De Pessoas a Pastéis: um olhar sobre o palmito na } \\
\text { região do médio vale do Itajaí/SC }\end{array}$ & $\begin{array}{l}\text { Orientadora: Júlia Guivant; } \\
\text { co-orientador: Gilberto F. } \\
\text { dos Santos }\end{array}$ \\
\hline 2002 & lara Thielen & $\begin{array}{l}\text { Percepções de Motoristas sobre o Excesso de } \\
\text { Velocidade no Trânsito de Curitiba - Paraná/Brasil }\end{array}$ & $\begin{array}{lr}\text { Orientador: } & \text { Fernando } \\
\text { Pires; } & \text { co-orientadora: } \\
\text { Maria Teresa } & \text { Castelo } \\
\text { Branco } & \end{array}$ \\
\hline 2002 & $\begin{array}{l}\text { Elza } \\
\text { Falkembach }\end{array}$ & $\begin{array}{l}\text { Sujeitos Sem-Terra em Movimento: socialização e } \\
\text { individuação }\end{array}$ & $\begin{array}{l}\text { Orientador: } \quad \text { Selvino } \\
\text { Assmann; co-orientador: } \\
\text { Paulo Krischke }\end{array}$ \\
\hline 2002 & $\begin{array}{l}\text { Susana Regina } \\
\text { de Mello } \\
\text { Schlemper }\end{array}$ & $\begin{array}{l}\text { As Cores das Marés: a construção cultural do } \\
\text { conhecimento sobre as marés vermelhas }\end{array}$ & $\begin{array}{l}\text { Orientador: Fernando } \\
\text { Pires; co-orientador: Luiz } \\
\text { A. Proença }\end{array}$ \\
\hline 2002 & $\begin{array}{l}\text { José Álvaro de } \\
\text { Lima Cardoso }\end{array}$ & $\begin{array}{l}\text { Reestruturação Produtiva e Mudanças no Mundo do } \\
\text { Trabalho: um olhar sobre os setores têxtil e alimentício } \\
\text { em Santa Catarina }\end{array}$ & $\begin{array}{l}\text { Orientador: Fernando P. } \\
\text { de Sousa; co-orientador: } \\
\text { Selvino Assmann }\end{array}$ \\
\hline 2002 & $\begin{array}{l}\text { Michele } \\
\text { Catherin }\end{array}$ & $\begin{array}{l}\text { Anos Potenciais de Vida Perdidos: a herança dos } \\
\text { acidentes de trânsito para as gerações futuras: uma }\end{array}$ & $\begin{array}{lr}\text { Orientador: } & \text { Fernando } \\
\text { Pires; } & \text { co-orientador: }\end{array}$ \\
\hline
\end{tabular}

Cad. de Pesq. Interdisc. em Ci-s. Hum-s., Florianópolis, v.10, n.97, p. 27-52, jul./dez. 2009 


\begin{tabular}{|c|c|c|c|}
\hline & Henrique & abordagem interdisciplinar. & Alberto Cupani \\
\hline 2002 & $\begin{array}{l}\text { Valmir Luiz } \\
\text { Stropasolas }\end{array}$ & $\begin{array}{l}\text { O Mundo Rural no Horizonte dos Jovens: o caso dos } \\
\text { filhos(as) de agricultores familiares de Ouro/SC }\end{array}$ & $\begin{array}{l}\text { Orientadora: Maria lgnez } \\
\text { S. Paulilo; co-orientador: } \\
\text { Bernard Roux }\end{array}$ \\
\hline 2002 & $\begin{array}{l}\text { Francisco José } \\
\text { Barretto da } \\
\text { Silva }\end{array}$ & $\begin{array}{l}\text { Conflitos de Uso em Área de Proteção Ambiental: Água, } \\
\text { Mineração e Agricultura }\end{array}$ & $\begin{array}{l}\text { Orientador: } \quad \text { Luiz } \mathrm{F} \text {. } \\
\text { Scheibe; } \\
\text { Antonio C. Diegues }\end{array}$ \\
\hline 2002 & $\begin{array}{l}\text { Ari Miguel } \\
\text { Teixeira Ott }\end{array}$ & $\begin{array}{l}\text { Dos Projetos de Desenvolvimento, ao Desenvolvimento } \\
\text { dos Projetos: O Planafloro em Rondônia }\end{array}$ & $\begin{array}{l}\text { Orientador: Paulo Freire } \\
\text { Vieira; co-orientador: } \\
\text { Ricardo Ventura Santos }\end{array}$ \\
\hline 2001 & $\begin{array}{l}\text { Cláudia Regina } \\
\text { dos Santos }\end{array}$ & $\begin{array}{l}\text { A Interface das Políticas Públicas com o Processo de } \\
\text { Ocupação Humana na Área de Preservação } \\
\text { Permanente: vegetação fixadora de dunas na Ilha de } \\
\text { Santa Catarina/SC. }\end{array}$ & $\begin{array}{l}\text { Orientador: } \quad \text { Fernando } \\
\text { Pires; co-orientador: João } \\
\text { de } \quad \text { Deus } \quad \text { Medeiros }\end{array}$ \\
\hline 2001 & $\begin{array}{l}\text { Alícia Norma } \\
\text { Gonzalez de } \\
\text { Castells }\end{array}$ & $\begin{array}{l}\text { A Criatividade dos Sem-Terra na Construção do Habitat - } \\
\text { um olhar etnográfico sobre a dimensão espacial do MST }\end{array}$ & $\begin{array}{l}\text { Orientadora: Júlia Guivant; } \\
\text { co-orientadora: Esther } \\
\text { Jean Langdon }\end{array}$ \\
\hline 2001 & $\begin{array}{l}\text { Vicente Volnei } \\
\text { de Bona Sartor }\end{array}$ & $\begin{array}{l}\text { Justiça Intergeracional e a Tradição da Política Brasileira } \\
\text { - A legislação e a política das águas no Brasil à luz da } \\
\text { teoria da justiça de John Rawls }\end{array}$ & $\begin{array}{l}\text { Orientadora: Sonia Felipe; } \\
\text { co-orientador: Luiz F. } \\
\text { Scheibe }\end{array}$ \\
\hline 2001 & Ariane Kuhnen & $\begin{array}{l}\text { Representações Sociais de Meio Ambiente: estudo das } \\
\text { transformações, apropriações e modos de vida na Lagoa } \\
\text { da Conceição/Fpólis-SC }\end{array}$ & $\begin{array}{l}\text { Orientadora: Ilse Scherer- } \\
\text { Warren; co-orientadora: } \\
\text { Louise Lhullier }\end{array}$ \\
\hline 2001 & João Fert Neto & $\begin{array}{l}\text { Problemas Ambientais Rurais e Mudanças Sócio- } \\
\text { Técnicas: A trajetória da piscicultura orgânica em SC }\end{array}$ & $\begin{array}{l}\text { Orientadora: Júlia Guivant; } \\
\text { co-orientador: Paulo Belli } \\
\text { Filho }\end{array}$ \\
\hline 2000 & $\begin{array}{l}\text { Sérgio Luís } \\
\text { Boeira }\end{array}$ & $\begin{array}{l}\text { Atrás da Cortina de Fumaça: tabaco, tabagismo e meio } \\
\text { ambiente - estratégias da indústria e dilemas da crítica }\end{array}$ & $\begin{array}{l}\text { Orientadora: Júlia Silvia } \\
\text { Giuivant; co-orientador: } \\
\text { Alberto Cupani }\end{array}$ \\
\hline 2000 & $\begin{array}{l}\text { Luís Alejandro } \\
\text { Vinatea Arana }\end{array}$ & $\begin{array}{l}\text { Modos de Apropriação e Gestão Sustentável de } \\
\text { Recursos Aquáticos Costeiros }\end{array}$ & $\begin{array}{ll}\text { Orientador: } & \text { Paulo Freire } \\
\text { Vieira; } & \text { co-orientador: } \\
\text { Alberto Cupani }\end{array}$ \\
\hline 1999 & Paula Brügger & Uma Leitura Ambientalista da Comunicação no Ocidente & $\begin{array}{l}\text { Orientador: } \quad \text { Paulo } \\
\text { Krischke; co-orientadora: } \\
\text { Maria Bernadete R. Flores }\end{array}$ \\
\hline 1999 & $\begin{array}{l}\text { Ana Márcia } \\
\text { Silva }\end{array}$ & $\begin{array}{l}\text { O Corpo do Mundo: reflexões acerca da expectativa de } \\
\text { corpo na modernidade }\end{array}$ & $\begin{array}{l}\text { Orientador: Selvino } \\
\text { Assmann; co-orientadora: } \\
\text { Carmen Lúcia Soares }\end{array}$ \\
\hline 1999 & $\begin{array}{l}\text { Gilberto } \\
\text { Montibeller } \\
\text { Filho }\end{array}$ & O Mito do Desenvolvimento Sustentável & $\begin{array}{l}\text { Orientador: } \quad \text { Luiz } F \text {. } \\
\text { Scheibe; } \quad \text { co-orientador: } \\
\text { Selvino Assmann }\end{array}$ \\
\hline
\end{tabular}

Quadro 1: Relação de teses defendidas de 1999 a 2007.

Fonte: site do programa: www.cfh.ufsc.br/ dich/, acessado em novembro de 2007.

A ementa desta área propõe que o

estudo interdisciplinar da problemática sócio-ambiental em sentido amplo dentro do debate sobre a globalização dos riscos e dos desafios sobre a sua governabilidade, com destaque para temas teóricos e aplicados relacionando qualidade de vida com avaliação de impactos ambientais, planejamento ambiental, desenvolvimento sustentável, papel das ciências na análise dos problemas ambientais e tecnológicos e aspectos éticos destas questões (Fonte: www.cfh.ufsc.br/ dich/, acessado em novembro de 2007).

Atualmente, os trabalhos da de área SMA estão dentro de duas linhas de pesquisa: Desenvolvimento, conflitos e políticas públicas (DCPP) com ementa focando

Cad. de Pesq. Interdisc. em Ci-s. Hum-s., Florianópolis, v.10, n.97, p. 27-52, jul./dez. 2009 
o "desenvolvimento sustentável como proposta de gestão territorial urbana e rural; o desenvolvimento e gestão participativos; a agricultura e meio ambiente; os conflitos ambientais rurais e urbanos; a avaliação de políticas públicas frente a problemas ambientais e; a governabilidade ambiental global" e Consumo, estilos de vida e ética (CEV), com a ementa englobando a "modernidade, globalização e consumo; a produção, consumo e simbolismo dos alimentos e outros bens; as relações entre consumo e estilo de vida; a ética e responsabilidade empresarial; a ética e justiça global, alcances e limites; os direitos humanos e direitos animais; o papel da ciência na gestão ambiental; a construção social dos riscos ambientais e tecnológicos e redes sócio-técnicas". (Fonte: www.cfh.ufsc.br/ dich/, acessado em novembro de 2007).

Com relação ao engajamento metodológico, é salientado na maioria das teses defendidas no $\mathrm{PICH}$, que não podemos ter a ilusão de fazer uma síntese de várias correntes, pois, como aponta Héctor Ricardo Leis (2005), sempre privilegiamos nossa formação de origem, apenas somando outras perspectivas e caminhos possíveis. É exatamente isto que encontramos na análise das teses de Sociedade e Meio Ambiente.

Há uma plasticidade nas análises, mas, no entanto, percebe-se as hierarquias bem definidas. Para Laymert Garcia dos Santos (1994):

\footnotetext{
O TODO é uma realidade fugaz, porque está sempre se desfazendo para voltar a se fazer. O TODO é algo que está sempre buscando ser outro, mas para se tornar, de novo, um OUTRO TODO (...). Há alguns autores que dizem que o TODO não existe, mas apenas a nossa construção dele (1994, p. 165).
}

O autor também destaca que "um método é um conjunto de proposições (coerentes entre si) que um autor ou um conjunto de autores apresenta para o estudo de uma realidade. Nenhum método é eterno" (SANTOS, 1994, p.166).

Com relação à construção do conhecimento, Hannah Arendt (1983, p.309) argumenta que a "mudança do 'por que' e do 'o que' para o 'como' implica que os verdadeiros objetos do conhecimento já não são coisas ou movimentos eternos, mas processos, e, portanto o objeto da ciência já não é a natureza ou o universo, mas a história - a história de como vieram a existir a natureza, a vida ou o universo".

Para Michel De Certeau et all. (1996) há uma ordem das práticas articuladas pelo discurso e muitas vezes a racionalidade científica tenta transformar o saber em fazer 
pelo método. Nas investigações de caráter interdisciplinar não existem fronteiras rígidas entre método e a investigação em si.

Nessa perspectiva, o "método" deixa, portanto, de ser algo pronto e um mero recurso para atingir determinados objetivos e passa a ser parte integrante do próprio estudo, ou seja, além de meio, ele compõe a abordagem e a reflexão em si. Objetividade, método e cientificidade estão inextricavelmente inter-relacionados.

Paula Brügger (1999) salienta que "o saber-fazer interdisciplinar não deveria se transformar num modismo acadêmico, num mero exercício intelectual, mas se comprometer sobretudo com os 'para quês' e 'para quens' das pesquisas realizadas".

Entre as teses analisadas, os autores que se baseiam em Frijof Capra (2003) apontam que para orientar a interdisciplinaridade, a idéia da "teoria dos sistemas" é possível de ser utilizada como uma abstração muito apropriada para a abordagem interdisciplinar de questões complexas. Para este autor, o desafio a caminho da interdisciplinaridade é entender que a educação deve mover seus pressupostos filosóficos em direção a uma cultura sustentável, buscando questionar os conceitos que se encontram mais solidamente sedimentados em nossas mentes, incluindo a forma como construímos o conhecimento. Nesse processo é fundamental, também, que percebamos o mundo de forma mais sistêmica ou ecológica (CAPRA, 2003).

Partindo da discussão que Leis (2005) faz em seu artigo sobre interdisciplinaridade, percebemos que no $\mathrm{PICH}$ há um movimento no sentido de transpor as fronteiras artificiais do conhecimento e que as teses refletem trabalhos de caráter transdisciplinar. Nas teses analisadas podemos encontrar características que refletem os três conceitos de interdisciplinaridade trazidos por esse autor: teses que refletem mais o conceito francês, o norte americano e o brasileiro, marcados respectivamente pela lógica racional, instrumental e subjetiva.

No artigo de Sônia Felipe (2005) acerca da interdisciplinaridade e a teoria crítica da sociedade em Max Horkheimer, vemos reforçada a importância do trabalho coletivo. Ela aponta que a pesquisa na filosofia deve estar ligada a objetos concretos de investigação para vim a se tornar a crítica dialética interdisciplinar desse objeto. $O$ texto aponta que o objeto de investigação deve poder ser visto e analisado sob perspectivas 
distintas de investigadores disciplinares, dispostos a trocarem entre si as informações que seus olhares disciplinares obtêm da investigação do objeto em particular. Assim, ela traduz a interdisciplinaridade como "um método de trabalho coletivo de diferentes investigadores na pesquisa de um único objeto" (FELIPE, 2005, p. 2).

Apresentado este panorama, o presente artigo pretende analisar como a interdisciplinaridade tem sido tratada no Programa de Doutorado Interdisciplinar de Ciências Humanas da UFSC, na área SMA, a partir da análise das teses defendidas de 1999 a 2007.

\section{ANÁLISE DAS TESES DEFENDIDAS DE 1999 A 2007}

Uma metáfora utilizada na tese de Brügger (1999) para apresentar a interdisciplinaridade foi a do vôo da águia, que vê o ecossistema e o objeto ao mesmo tempo. Como a autora coloca, temos que tentar alçar vôos mais altos que permitam ver além das cavernas (aludindo ao mito da Caverna de Platão) disciplinares às quais estamos presos. Estes vôos, no entanto, não ficam na superficialidade de ver acima o todo, com uma abordagem positivista e fragmentada, mas além do todo analisar a parte que realmente importa sob várias correntes de pensamento.

O método é entendido pela maioria dos autores analisados como um caminho a ser seguido ou trilhado para se chegar a um determinado objetivo. Para ser interdisciplinar deve apresentar uma visão do objeto, abordando as dimensões de espaço e tempo conectadas e aprofundadas, mesclando as fronteiras disciplinares.

Esta mescla de fronteiras se deu nas teses, mais efetivamente, pelo diálogo de duas ou mais áreas do conhecimento. Normalmente o/a doutorando/a analisa um objeto da sua área de formação ou de experiência profissional, articulando com disciplinas da área de Ciências Humanas.

As disciplinas/áreas que os/as autores/as articularam em suas teses que se apresentam de forma mais destacada foram: Sociologia, Antropologia,

Ecologia/Ambiental, Educação, História, Filosofia, Geografia, Economia e Comunicação, em diferentes vertentes. No quadro 02, está relacionada (para um grupo 
de doze teses dentre as vinte e quatro analisadas) a freqüência em que as disciplinas são citadas comparando com a freqüência em que as mesmas são consideradas o foco principal da tese, como a disciplina principal em uma hierarquia entre todas citadas na tese.

\begin{tabular}{|c|c|c|c|}
\hline \multirow{2}{*}{$\begin{array}{c}\text { Disciplinas/Área do } \\
\text { Conhecimento }\end{array}$} & \multicolumn{2}{|c|}{ Hierarquia entre as Disciplinas na Tese } & \multirow{2}{*}{$\begin{array}{l}\text { Área de Formação } \\
\text { da/o Doutoranda/o }\end{array}$} \\
\hline & $\begin{array}{l}\text { Freqüência de citações } \\
\text { enquanto Área de } \\
\text { Conhecimento }\end{array}$ & $\begin{array}{c}\text { Freqüência } \\
\text { enquanto Área } \\
\text { priorizada na Tese }\end{array}$ & \\
\hline Sociologia & 11 & 06 & 01 \\
\hline Psicologia & 03 & 01 & 01 \\
\hline Antropologia & 05 & 03 & 01 \\
\hline História & 07 & - & - \\
\hline Filosofia & 02 & 01 & - \\
\hline Geografia & 04 & - & - \\
\hline Educação/Pedagogia & 03 & 02 & 03 \\
\hline Agronomia & 01 & - & 02 \\
\hline Economia & 03 & 02 & 01 \\
\hline Ecologia/Ambiental & 08 & 03 & 01 \\
\hline Arquitetura/Urbanismo & 01 & 01 & - \\
\hline Medicina & - & - & 01 \\
\hline Designer & - & - & 01 \\
\hline
\end{tabular}

Quadro 2: Freqüência das disciplinas/áreas do conhecimento em 12 teses analisadas relacionadas com área de formação do/a Doutorando/a

Fonte: Planilhas de análise das teses confeccionada pelas discentes Ivana Lovo e Mariuze Mendes.

Os objetivos expressos nas teses parecem indicar a possibilidade de novas leituras e novas compreensões de temas, graças ao aporte de diversas disciplinas nas referências teóricas. Esta tendência é percebida também nas perguntas de pesquisa, que ganham em complexidade, graças à abordagem interdisciplinar.

Possibilidades de reinterpretação do cotidiano são apontadas nas teses de Ariane Kuhnen (2001), Alícia Norma Gonzalez Castells (2001), Ângela Maria de Moraes Bertho (2005) e Ana Lúcia Santos Verdasca Guimarães (2007). Esta apresenta os significados dos arranjos espaciais e dos objetos em interiores domésticos, abordando este tema na intersecção de saberes das áreas de Design, Sociologia e Antropologia, considerando os aspectos culturais da negociação dos espaços. Interessante apontar nesta tese algo que se reflete em tantas outras: a necessidade de avançar para as áreas fronteiriças, buscando ampliar as possibilidades, reconhecendo a necessidade de compreensão de elementos de diferentes áreas. 
As áreas fronteiriças não demarcam limites, mas hibridações, o que também está apontado em Kuhnen (2001), Castells (2001) e Bertho (2005), que analisam nas teses a apropriação e construção de espaços coletivos a partir de negociações e conflitos. Estudando, sucessivamente, a apropriação do espaço da Lagoa da Conceição; a demarcação de áreas de assentamento dos "sem-terra" em SC; dos "indígenas" da Serra dos Tabuleiros. Nestas teses, a Geografia, a Arquitetura, Antropologia Cultural e Sociologia são áreas de análise da configuração de espaços exteriores coletivos, de forma crítica, levando em consideração as políticas públicas e questões ambientais envolvidas.

As teses do PICH, citando Ana Lúcia Santos Verdasca Guimarães (2007), em geral adotam "uma visão construtivista, ao considerar que os objetos não são apenas construídos pelas pessoas, mas igualmente as constroem", abordagem que se encontra nas teses apoiada em contribuições de "autores que estudaram temas semelhantes ou afins".

Foi evidenciada nas teses analisadas esta possibilidade de trabalhar com autores que "costurem" a interdisciplinaridade em seus textos e métodos e que abordem os pontos-chave da investigação de forma interdisciplinar, considerando diferentes tradições filosóficas, como uma condição sine qua non para o florescimento de novas idéias.

\section{REFLETINDO SOBRE A ABORDAGEM INTERDISCIPLINAR NAS TESES}

Com base nas teses analisadas, podemos fazer as seguintes constatações gerais sobre a questão de como a interdisciplinaridade tem sido construída no Programa Interdisciplinar em Ciências Humanas (PICH):

- É relevante a origem dos/as autores/as, sua história acadêmica e também de vida, dando uma importante conotação e direção para a forma e como o trabalho é desenvolvido. Isto é refletido na escolha do problema, na metodologia e na elaboração da dissertação propriamente dita; 
- Percebe-se que a origem dos autores/as, sua área de atuação está refletida na temática escolhida e na definição dos lugares estudados, havendo uma inserção prévia no universo pesquisado;

- O perfil dos(as) orientadores(as) e co-orientadores (as), facilitam ampliar o leque de abordagens do estudo;

- O caráter qualitativo das dissertações é predominante, aparecendo os dados quantitativos apenas como fontes citadas de censos ou dados produzidos em outros contextos e utilizados na tese para auxiliar o estudo e análise do problema que está sendo pesquisado;

- É principalmente na revisão bibliográfica que é mostrado o caráter interdisciplinar do tema escolhido, ficando o grau interdisciplinar do estudo marcado pela diversidade de autores citados e ou áreas do conhecimento abordadas na dissertação;

- O enfoque interdisciplinar envolve as áreas de história, sociologia, filosofia, geografia, antropologia, economia, comunicação, ecologia/ambiental, mas em algumas situações tem-se um caráter mais multidisciplinar do que interdisciplinar nas dissertações;

- A hierarquia entre os conhecimentos fica implícita pela origem da formação do pesquisador e pelo volume de autores pesquisados em determinada área;

- A pergunta norteadora da pesquisa nem sempre está explicita no trabalho;

- Muito raramente houve o destaque do item "metodologia", muitas vezes, os elementos compatíveis a esse aparecem principalmente na "introdução", ou, pulverizados em todo o trabalho.

- Na ausência do item denominado "metodologia", a interdisciplinaridade tem que ser "captada" nas demais partes da tese;

- Verificou-se que a entrevista é a ferramenta e estratégia mais constante de coleta de dados, foram citadas entrevista semi-estruturada e/ou semi-diretivas, etnografia, observação participante, entrevistas espontâneas ou focadas, com roteiro baseado em protocolo de estudo de caso, historiografia, construção da narrativa da experiência pelos autores com perguntas orientadoras. As 
entrevistas são complementadas com técnicas de observação direta, registros fotográficos, observação participante e análise de artefatos;

- Outra estratégia metodológica explorada foi o uso de imagens fotográficas como mediadoras do diálogo com os entrevistados e como forma de análise de configurações espaciais exteriores e interiores, na relação com as configurações sociais. Espaço e temporalidade são relacionados e considerados como determinantes de redes de sociabilidade e deslocamentos sociais.

- Há o uso tanto de categorias teóricas quanto nativas ou práticas, e ainda de ambas na estruturação das discussões e análises, dependendo do perfil da pesquisa realizada;

- No plano de análise dos dados a interdisciplinaridade é observada na forma de se proceder as sistematizações e análises. Foi verificado o uso de relações entre conceitos síntese, ou seja, buscar pressupostos teóricos e históricos para fazer leitura crítica de fatos, concepções e conceitos para compreender como estes operam e orientam o problema analisado; a confluência de abordagens, ou seja, a busca de consensos e análise entre autores diferentes e; a triangulação entre teoria mobilizada ou constituída, o método utilizado e os fenômenos sociais abordados.

Com base na "crítica dialética interdisciplinar", citada por Felipe (2005), constatamos que nas teses analisadas nem sempre fica explicita essa prática, já que a elaboração da tese é um processo individual sendo discutida no contexto da orientação e co-orientação. A perspectiva do diálogo entre diferentes disciplinas e ou áreas de conhecimento ocorre no processo reflexivo do/a autor/a da tese com teóricos da área de estudo e com sua orientação. Raramente compartilha, na elaboração da tese, idéias com outros pesquisadores e estudiosos, de diferentes áreas, sobre o entendimento e análise do mesmo objeto de estudo, como sugere a crítica reflexiva interdisciplinar.

A perspectiva da crítica dialética interdisciplinar tem o potencial de ser praticada dentro das atividades dos grupos de pesquisa coordenados pelos professores orientadores, co-orientadores ou mesmo professores constituintes das bancas, tanto da 
qualificação quando da defesa de tese. Poderíamos caracterizar a qualificação e a defesa como exercícios de um trabalho coletivo, de diferentes investigadores, no debate de um único objeto, a tese. Nessa perspectiva, é nestes momentos, a partir da constituição de uma banca com profissionais de diferentes áreas, que ocorrem os únicos momentos em que um diálogo interdisciplinar é travado especificamente sobre o tema da tese.

\section{CONSIDERAÇÕES}

O resultado deste ensaio aponta que nas pesquisas há muito mais uma proposta de olhar interdisciplinar do que propriamente a definição de um objeto ou de um caminho único para a interpretação do mesmo. Alguns conceitos-chave na interdisciplinaridade ambiental são identificados nas teses da área SMA como, por exemplo, a idéia de sustentabilidade.

Dessa forma, se faz necessário pensar uma sustentabilidade em diversos contextos, permitindo, nos moldes de Enrique Leff (2006), uma Racionalidade Ambiental que se "constrói integrando as esferas de racionalidade teórica, substantiva, material, instrumental e cultural [...] onde os valores se convertem em princípios produtivos que dão coerência a uma nova teoria da produção" (LEFF, 2006, p. 264).

Tal constatação nos traz a preocupação de repensar a própria Ciência no século XXI e seu papel social (PENA-VEGA, 2003, p.53).

[...] essa ciência elucidativa, enriquecedora, conquistadora e triunfante, apresenta-nos, cada vez mais, problemas graves que se referem ao conhecimento que produz, à ação que determina, à sociedade que transforma. Essa ciência libertadora traz, ao mesmo tempo, possibilidades terríveis de subjugação. Esse conhecimento vivo é o mesmo que produziu a ameaça do aniquilamento da humanidade. Para conceber e compreender esse problema, há que acabar com a tola alternativa da ciência "boa", que só traz benefícios, ou da ciência "má", que só traz prejuízos. Pelo contrário, há que, desde a partida, dispor de pensamento capaz de conceber e de compreender a ambivalência, isto é, a complexidade intrínseca que se encontra no cerne da ciência (MORIN, 2001, p.16).

Para compreensão do saber é imprescindível que sejam reatados novamente indivíduo/sociedade/espécie, para que se opere a sua relação permanente e simultânea

Cad. de Pesq. Interdisc. em Ci-s. Hum-s., Florianópolis, v.10, n.97, p. 27-52, jul./dez. 2009 
como no princípio dos tempos. Assim ao perguntarmos, "O que é a ciência?", percebemos, ou devemos perceber, que essa questão não tem uma resposta científica: a ciência não se conhece cientificamente e não tem nenhum meio de se conhecer cientificamente (MORIN, 2001).

Através das análises efetivadas constata-se que, para compreensão da relação entre "sociedade" e "meio ambiente", os alunos do Doutorado Interdisciplinar em Ciências Humanas (DICH) buscam uma visão interdisciplinar que perceba uma Epistemologia Ambiental Complexa. Nesse sentido, é necessária a percepção de uma ciência que comunique saberes e considere complexidades e comunicação entre saberes. Assim, ficamos ainda com a lição de Thomas Kuhn (1992), que destaca:

\begin{abstract}
O historiador da ciência que examinar as pesquisas do passado a partir da perspectiva da historiografia contemporânea pode sentir-se tentado a proclamar que, quando mudam os paradigmas, muda com eles o próprio mundo. Guiados por um novo paradigma, os cientistas adotam novos instrumentos e orientam seu olhar em novas direções. E o que é ainda mais importante: durante as revoluções, os cientistas vêem coisas novas e diferentes quando, empregando instrumentos familiares, olham para os mesmos pontos já examinados anteriormente. É como se a comunidade profissional tivesse sido subitamente transportada para um novo planeta, onde objetos familiares são vistos sob uma luz diferente e a ele se apregam objetos desconhecidos. (...) Não obstante, as mudanças de paradigma levam os cientistas a ver o mundo, definido por seus compromissos de pesquisa, de uma maneira diferente (KUHN, 1992, p.145-146)
\end{abstract}

A análise das teses defendidas na área SMA indica algumas tendências da interdisciplinaridade no âmbito desse programa de pós-graduação. A primeira delas é que as propostas partem de autores das mais diversas áreas científicas, que pretendem basicamente entender de forma mais complexa os objetos que se propõem a estudar.

Compreender como a interdisciplinaridade é construída em cada programa auxilia na busca da consolidação das experiências interdisciplinares no âmbito da pósgraduação no Brasil. Possibilita, outrossim, avaliar em que medida se sinaliza para uma nova forma de construir o conhecimento científico e de intervir na realidade, distante da fragmentação e especialização da ciência moderna e do conforto da especialização.

Cad. de Pesq. Interdisc. em Ci-s. Hum-s., Florianópolis, v.10, n.97, p. 27-52, jul./dez. 2009 


\section{REFERÊNCIAS}

BAKHTIN, M. Questões de Literatura e de estética: a teoria do romance. São Paulo: Hucitec, 2002.

BECK, U. A reinvenção da política: rumo a uma teoria da modernização reflexiva. In: BECK, U.; GIDDENS, A.; LASH, S. Modernização reflexiva: política, tradição e estética na ordem social moderna. São Paulo: Editora da Universidade Estadual Paulista, 1997. p.11-72

BERTHO, A. M. M. Os Índios Guarani na Serra do Tabuleiro e a conservação da Natureza - etnohistória/cosmologia/territorialidade/manejo agroflorestal/sustentabilidade etnoambiental. 2005. Tese (Doutorado) - Universidade Federal de Santa Catarina. Centro de Filosofia e Ciências Humanas. Programa de Pós-Graduação Interdisciplinar em Ciências Humanas, Florianópolis, 2005.

BHABHA, H. K. O Pós-colonial e o Pós-Moderno. A questão da Agência. In: . 0 Local da Cultura. Belo Horizonte, Editora da UFMG, 2001. p 239-273

BOURDIEU, P. Struture, habitus, pratiques. In: . Le sens pratique. Paris, Editions de Minuit, 1980. p 87-110.

BRÜGGER, P. Uma Leitura Ambientalista da Comunicação no Ocidente. 1999. Tese (Doutorado) - Universidade Federal de Santa Catarina. Centro de Filosofia e Ciências Humanas. Programa de Pós-Graduação Interdisciplinar em Ciências Humanas, Florianópolis, 1999.

CANCLINI, N. G. Culturas Híbridas: estratégias para entrar e sair da modernidade. São Paulo: Edusp, 1997.

CAPRA, F. A teia da vida. São Paulo: Cultrix, 2003.

CASTELLS, A. N. G. A Criatividade dos Sem-Terra na Construção do Habitat - um olhar etnográfico sobre a dimensão espacial do MST. 2001. Tese (Doutorado) Universidade Federal de Santa Catarina. Centro de Filosofia e Ciências Humanas. Programa de Pós-Graduação Interdisciplinar em Ciências Humanas, Florianópolis, 2001.

COIMBRA, J. de A. A. Considerações sobre a interdisciplinaridade. In: PHILIPPI Jr., A. (org.) Interdisciplinaridade em Ciências Ambientais. São Paulo: Signus Editora, 2000. p.52-70.

DE CERTEAU, M.; GIARD, L.; MAYOL, P. A Invenção do Cotidiano 2: morar, cozinhar. Rio de Janeiro: Vozes, 1996. 
FELIPE, S. T. Interdisciplinaridade e teoria crítica da sociedade em Max Horkhemer. Palestra apresentada na mesa redonda sobre interdisciplinaridade Simpósio dos 10 anos do Doutorado Interdisciplinar em Ciências Humanas da UFSC. Florianópolis: Hotel Maria do Mar, 11/11/2005, 17:30-20:00 hs.

FOUCAULT, M. A Arqueologia do Saber. Trad. de Luiz Felipe Baeta neves. $7^{\circ}$ ed. Rio de Janeiro: Forense Universitária, 2004.

GIDDENS, A. A terceira via: Reflexões sobre o impasse político atual e o futuro da social democracia. Rio de Janeiro: Record, 1999.

GUATARRI, F. Caosmose: Um novo paradigma estético. São Paulo: Ed. 34, 1992.

GUIMARÃES, A. L. S. V. Design, Sociedade e Cultura: significados dos arranjos espaciais e dos objetos em interiores domésticos. 2007. Tese (Doutorado) Universidade Federal de Santa Catarina. Centro de Filosofia e Ciências Humanas. Programa de Pós-Graduação Interdisciplinar em Ciências Humanas, Florianópolis, 2007.

HALL, S. Da Diápora: Identidades e Mediações Culturais. Belo Horizonte: Editora UFMG, 2003.

KUHN, T. A estrutura das Revoluções Científicas. Trad. Beatriz Vianna Boeira e Nelson Boeira. São Paulo: Perspectiva, 1992.

KÜHNEN, A. Representações Sociais do Meio Ambiente: estudo das transformações, apropriações e modos de vida na Lagoa da Conceição, Florianópolis/SC. 2001. Tese (Doutorado) - Universidade Federal de Santa Catarina. Centro de Filosofia e Ciências Humanas. Programa de Pós-Graduação Interdisciplinar em Ciências Humanas, Florianópolis, 2001.

LE GOFF, J. História e Memória. São Paulo: Editora da UNICAMP, 1990.

LEFF, E. Complexidade, interdisciplinaridade e saber ambiental. In: PHILIPPI Jr., A. (org.) Interdisciplinaridade em Ciências Ambientais. São Paulo: Signus Editora, 2000. p.19-51

. Racionalidade Ambiental: A Reapropriação Social da Natureza. Rio de Janeiro: Civilização Brasileira, 2006.

LEIS, H. R. Sobre o Conceito de Interdisciplinaridade. Cadernos de Pesquisa Interdisciplinar em Ciências Humanas, v.6, n.73, 2005. Disponível em: http://www.cfh.ufsc.br/ dich/cadernos.htm. Acesso em dez de 2007. 
MORIN, E. Ciência com consciência. Tradução: Maria D. Alexandre e Maria Alice Sampaio Dória. $5^{\circ}$ ed. Rio de Janeiro: Bertrand Brasil, 2001.

. Introdução ao Pensamento Complexo. Trad. Dulce Matos. Lisboa: Instituto Piaget, 2003.

PENA-VEGA, A. O despertar ecológico: Edgar Morin e a ecologia complexa. Rio de Janeiro: Garamond, 2003.

Programa Interdisciplinar em Ciências Humanas. Disponível em $<$ http://www.cfh.ufsc.br/ dich/>. Acesso em 02 ago 2008

SANTOS, L. G. dos. Politizar as novas tecnologias: o impacto sócio-técnico da informação digital e genética. São Paulo: Ed. 34, 2003.

VELHO, G. Projeto, emoção e orientação em sociedades complexas. In: Individualismo e Cultura: notas para uma Antropologia da Sociedade Contemporânea. Rio de Janeiro: Jorge Zahar, 1987. p.13-37.

Artigo:

Recebido em: 31/08/2009

Aceito em: 05/11/2009 